\title{
The role of microductectomy in the diagnosis and treatment in women with pathologic nipple discharge
}

\author{
Aytaç Emre Kocaoğlu๑, Mehmet Mustafa Altıntaş๑, Fırat Mülkütø \\ Department of General Surgery, İstanbul Dr. Lütfi Kırdar Training and Research Hospital, İstanbul, Turkey
}

\begin{abstract}
Objectives: Approximately one tenth of the patients who apply to the breast polyclinics complain of nipple discharge. Apart from pregnancy and lactation, spontaneous, unilateral, bloody or serous discharge originating from a single duct describes the pathological nipple discharge (PND). The aim of this study is to show that precancerous breast lesions, which can be easily overlooked by conventional diagnostic methods, are detected with the microductectomy performed with the correct indication and it is possible to complete the appropriate treatment.

Methods: Fifty-five microductectomy procedures were performed in 55 female patients who applied to the relevant clinic with the complaint of nipple discharge between January 2013 and August 2018 and who met at least two of the three criteria of pathological nipple discharge (spontaneous, single ductus, bloody or serous) except pregnancy and lactation. Prospectively collected information was evaluated retrospectively.

Results: The average age of the patients in the study ranged from 23 to 73 years (mean age: 45.5 years; median age: 47 years). Out of 55 procedures, 28 (50.9\%) were performed in women of reproductive age, $27(49.1 \%)$ were performed in women in menopause. The discharge was localized to the right breast in 28 patients, and to the left breast in 27 patients. Forty-one of the 55 patients included in the study met all of the criteria for pathological nipple discharge, while the other 14 patients had at least two of the three criteria. Final pathologies were classified as follows; intraductal papilloma/papillomatosis with atypia, intraductal papillary carcinoma (IPC), ductal carcinoma in situ (DCIS), and potential neoplastic and malignant lesion (PNML).

Conclusions: In cases where direct intraductal imaging methods cannot be applied in patients admitted to the polyclinic with pathological nipple discharge, microductectomy emerges as an effective diagnosis and treatment method that can be applied with low morbidity.
\end{abstract}

Keywords: Pathological nipple discharge (PND), microductectomy, surgery

ntermittent or continuous nipple discharge is the third most common cause of complaints (up to $10 \%$ ) in women who apply to medical institutions with complaints of the breast, after breast pain and palpable mass. Most of the nipple discharge is physiological [1, 2]. Apart from pregnancy and lactation, spontaneous, unilateral discharge originating from a single duct describes pathological nipple discharge (PND) [3]. The secretion can be a serous, serosanguinous, bloody and purulent character. The most common cause of nipple discharge is benign breast lesions such as solitary intraductal papilloma and papillomatosis [4]. A rare but

How to cite this article: Kocaoğlu AE, Altıntaş MM, Mülküt F. The role of microductectomy in the diagnosis and treatment in women with pathologic nipple discharge. Eur Res J 2022;8(2):210-217. DOI: 10.18621/eurj.963567

Address for correspondence: Mehmet Mustafa Altıntaş, MD., Istanbul Dr. Lütfi Kırdar Training and Research Hospital, Department of General Surgery, İstanbul, Turkey

E-mail: mehmetal1@hotmail.com,Tel: +905052664636 
important cause of pathological nipple discharge is breast cancer, which accounts for $5-21 \%$ of these discharge [4-6].

In the diagnostic approach of PND, the imaging methods, following the complete history and physical examination, play a major role. The classical modalities preferred in these patients are mammography, ultrasonography (USG), magnetic resonance imaging (MRI), cytology of the discharge, fine needle aspiration biopsy (FNAB) and core biopsy. Mammography and USG are methods with low sensitivity in detecting very small intraductal lesions [7]. MRI may not always be successful in detecting all intraductal neoplasms $[8,9]$. Galactography is an imaging method used to visualize the lactiferous ducts, but the image is evaluated indirectly, not directly. Although the use of this modality increases the reliability of the diagnosis, it is insufficient to distinguish intraductal lesion from intraductal debris. Because galactography reports both situations as filling defects. Therefore, the general approach, used in the final diagnosis of women with pathological nipple discharge, is "canal excision" [10, 11]. Although its added value has not been accepted all over the world, breast ductoscopy is a new method that is increasingly used in the investigation of nipple discharge compared to other methods $[12,13]$. Unfortunately, ductoscopy can not be used due to uncommon and difficult to reach.

Within the scope of this study, among women who applied to the polyclinic with the complaint of nipple discharge, patients who described at least 2 criteria of pathological nipple discharge underwent microductectomy in the operating room environment. Pathology results of the patients were compared with preoperation imaging methods and cytology results. The adequacy of the surgical procedure was evaluated in patients with malignancy reported as a result of pathology. The relationship between the discharge criterion and malignancy was investigated and also the adequacy of microductectomy in symptomatic relief was examined.

\section{METHODS}

This study was conducted Breast and Endocrine Surgery Unit. It was approved by the local ethics committee of the institute. In addition, all patients were in- formed about the procedure and then signed an informed consent form.

Fifty-five microductectomy procedures were performed in 55 female patients who applied to the relevant clinic with the complaint of nipple discharge between January 2013 and August 2018 and who met at least two of the three criteria of pathological nipple discharge (spontaneous, single ductus, bloody or serous) except pregnancy and lactation. Prospectively collected information was evaluated retrospectively.

The patients included in the study were divided into groups according to how many PND criteria they met (PND $2+$ : those who meet any 2 of 3 criteria, PND 3 + : those who meet 3 criteria). Patients who had a palpable mass on physical examination, a solitary mass with suspicion of malignancy by imaging methods, and those who were found to have malignancy as a result of imaging-guided biopsy were excluded from the study.

The patients were divided into 3 groups according to their pathology results; Those with no intraductal lesions (ductal ectasia/periductal mastitis), those with benign intraductal lesions (intraductal papilloma and intraductal papillomatosis), those with pathogenic neoplastic and malignant lesions (DCIS, intraductal papillary carcinoma, atypical intraductal papilloma and atypical papilloma with atypical papilloma). The cytology results of nipple discharge of the patients were collected under 4 groups. These groups are; cytological findings including blood cells, cytological findings including inflammatory and normal ductus cells, papilloma suspicious cytological findings and cytological findings with atypical ductus cells. The USG and MRI results of the patients were coded under 4 groups. These 4 groups; normal USG and MRI findings, ductal ectasia, intraductal lesion, and malignancy suspicious findings. Mammography was coded according to the BIRAD-S system.

Isolated ductal lobular unit excision (microductectomy) was performed in patients who meet at least two criteria of pathological nipple discharge and who wanted symptomatic relief. The mentioned procedure was performed under general anesthesia and in the operating room. Stages of the microductectomy procedure are shown in Figs. 1 and 2).

\section{Statistical Analysis}

SPSS version 21 for Windows was used for statis- 

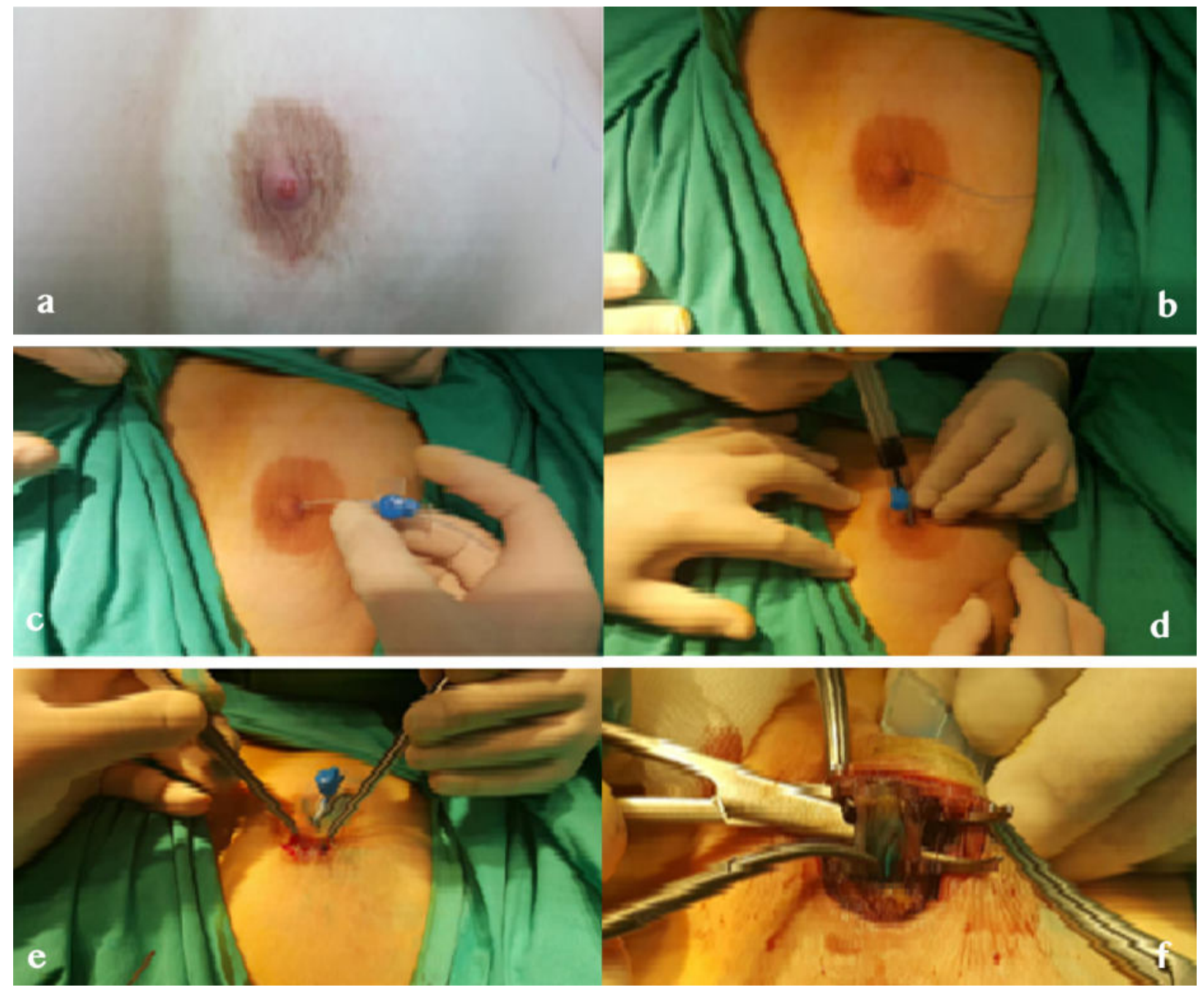

Fig. 1. Stages of the microductectomy procedure. (a) İsolated nipple discharge, (b) Cannulation of the duct with prolene, (c) Dilation of the duct with a branul cannula, (d) Staining of the duct with methylene blue, (e) Exploration with periareolar excision, and (f) Isolating the dyed duct.

tical calculations. Chi-Square and Fisher's exact tests were used for statistical analysis. A value of $p<0.05$ was considered significant.

\section{RESULTS}

Fifty-five patients who were operated on were evaluated postoperatively. The discharge of 54 patients stopped after the operation. A patient whose pathology had intraductal papillomatosis continued to discharge after the operation, and subareolar excision was performed as a second operation. The pathology result of the second operation was reported as a foreign reaction. No postoperative complications were observed in other patients. In one of the patients, re-excision was required when the surgical margin was positive
DCIS was seen in the pathology result.

The average age of the patients in the study ranged from 23 to 73 years (mean age: 45.5 years; median age: 47 years). Out of 55 procedures, $28(50.9 \%)$ were performed in women of reproductive age, 27 (49.1\%) were performed in women in menopause. The discharge was localized to the right breast in 28 patients, and to the left breast in 27 patients. Forty-one of the 55 patients included in the study met all of the criteria for pathological nipple discharge, while the other 14 patients had at least two of the three criteria (Tables 1 and 2).

Final pathologies were classified as follows; intraductal papilloma/papillomatosis with atypia, intraductal papillary carcinoma (IPC), ductal carcinoma in situ (DCIS), and potential neoplastic and malignant lesion (PNML). 


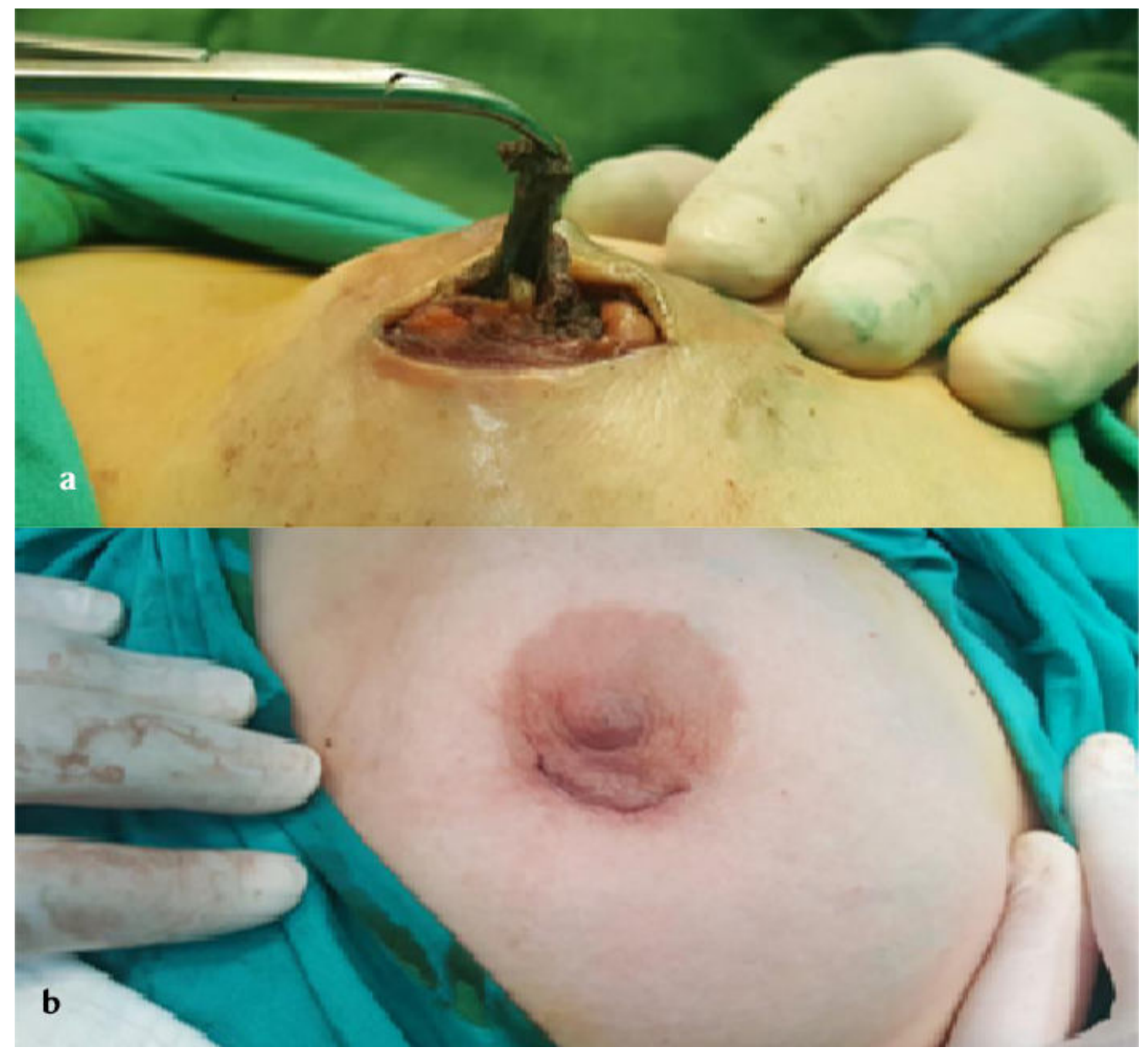

Fig. 2. The last stage of the procedure: isolated ductus excision. (a) Complete isolation and excision of the duct, (b) Closure of the skin.

All patients were evaluated ultrasonographic before the operation. Lesions (papillomatous lesion/PNML) were found in the pathologies of 21 $(61.7 \%)$ of 34 patients whose USG was reported as normal. Twelve of these patients were reported as intraductal papilloma, 4 as intraductal papillomatosis, and 5 as PNML. Seventeen patients with intraductal lesions detected on USG were reported. When the pathologies of these patients were examined, it was found that the following were reported; Ductal ectasia/periductal mastitis in $5(29.4 \%)$ patients, papillomatous lesion in $7(41.2 \%)$ patients, and PNML in 5 (29.4\%) patients.

Mammography was performed in 41 of 55 patients before the operation. Mammography was not requested for the other 14 patients due to their age. The pathology of 2 of 14 patients who did not undergo mammography were reported as DCIS. In 25 of 41 pa- tients who had mammography, its result was reported as BIRADS 0. DCIS was found in the pathology of 2 of these patients, intraductal papillary carcinoma in 1 , intraductal papilloma with atypia in 2 patients, and intraductal papillomatosis with areas of atypia in 1 . Mammography results of 8 of the other 16 patients were reported as BIRADS 1, 5 of them as BIRADS 2, 1 of them as BIRADS 3, and 2 of them as BIRADS 4a. In 7 out of 8 patients reported as BIRADS 1, intraductal lesion was shown pathologically. In 2 of 5 patients reported as BIRADS 2 and 1 patient reported as BIRADS 3, intraductal lesion was shown pathologically. PNML was not detected in any patient reported as BIRADS 1-2 and 3. DCIS was detected in one of the 2 patients reported as BIRADS $4 \mathrm{a}$, and intraductal papillary carcinoma was detected in the other.

MRI could not be performed in 2 of 55 patients included in the study due to claustrophobia. Pathology 
Table 1. Distribution of patients by discharge type

\begin{tabular}{lccc}
\hline & Total patients & $\begin{array}{c}\text { Number of patients } \\
\text { with lesions }\end{array}$ & $\boldsymbol{p}$ value \\
\hline $\begin{array}{l}\text { Pathological discharge } \\
\text { (cerotic, serosanguinous and bloody) }\end{array}$ & 47 & $34(72.3 \%)$ & $\boldsymbol{p}<\mathbf{0 . 0 1}$ \\
$\begin{array}{l}\text { Non-pathological discharge } \\
\text { (milky, green and brown) }\end{array}$ & 8 & $1(12.5 \%)$ \\
\hline
\end{tabular}

results of these patients were reported as ductal ectasia/periductal mastitis. In the pathology of 12 of 20 patients whose MRIs were reported as intraductal lesions, intraductal papillomatous lesions ( 9 solitary papilloma, 3 multiple papillomas), 2 had DCIS, 2 had intraductal papilloma with atypia, and 1 had papillomatous with atypical areas of papilloma.

In the other 3 patients, no intraductal lesions were detected (ductal ectasia/periductal mastitis). In the pathologies of 3 patients whose MRIs were reported as suspected malignancy; DCIS was found in 1 and ductal ectasia/periductal mastitis in the other 2. In the pathologies of 30 patients whose MRI results were reported as normal; 13 had intraductal papillary lesions (solitary papilloma/multiple papillomas in 10 patients), DCIS in 2, intraductal papillary carcinoma in 2, and ductal ectasia/periductal mastitis in the other 13 patients.

Preoperative nipple discharge cytology examination made in all patients included in the study. In the pathology of 7 of 9 patients with red blood cells on cytological examination, intraductal papilloma $(77.8 \%)$, intraductal papillary carcinoma $(11.1 \%)$, and ductal ectasia/periductal mastitis were detected in 1 (11.1\%). In the pathologies of 20 patients whose cytology results were reported as suspicious papilloma; While 10 had intraductal papillary lesions (solitary papilloma in 7 patients, multiple papillomas in patients), 6 patients PNML (2 patients DCIS, 1 patient intraductal papillary carcinoma, 2 patients intraductal papil- loma with atypia, 1 patient papillomatosis with atypical areas of papilloma). In 4 patients, no intraductal lesions were detected (ductal ectasia/periductal mastitis). Papillomatosis was detected in 1 of 2 patients and DCIS was detected in 1 of 2 patients with atypical ductus cells on cytological examination. When the pathologies of 24 patients with inflammatory cells and normal ductus cells on cytological examination were examined; There were no intraductal lesions in 15 of them (ductal ectasia/periductal mastitis), 7 had intraductal papillary lesions (solitary papillomas in 5 patients, multiple papillomas in 2 patients), and DCIS in 2 patients.

If 5 patients who underwent microductectomy and whose pathology result was reported as DCIS, and 2 patients whose pathology result was reported as intraductal papillary carcinoma, were examined, in six of these patients, adequate surgical margins were provided by microductectomy. Re-excision was performed in a patient with DCIS due to a positive surgical margin. After radiotherapy was applied to all patients, Tamoxifen or Aromatase inhibitor treatment was started depending on the menopause status.

\section{DISCUSSION}

Imaging methods are always helpful diagnostic methods. Physical examination and anamnesis are the most important elements in the correct diagnosis. Even

Table 2. Distribution of patients according to pathological nipple discharge

\begin{tabular}{cccc}
\hline $\begin{array}{c}\text { Pathological Nipple Discharge -PND } \\
\text { Single duct-Spontaneous-Pathological } \\
\text { discharge }\end{array}$ & Total patients & $\begin{array}{c}\text { Number of patients } \\
\text { with lesions }\end{array}$ & $\boldsymbol{p}$ value \\
\hline $\begin{array}{c}3+\text { criteria } \\
2+\text { criteria }\end{array}$ & 41 & $29(70.7 \%)$ & $P>0.05$ \\
\hline
\end{tabular}


if methods such as USG, mammography, breast MRI are found to be normal, it should always be kept in mind that there may be an underlying pathology.

Apart from pregnancy and lactation, spontaneous, unilateral, bloody or serous discharge originating from a single duct describes PND. Although the most common cause of pathological nipple discharge is benign breast lesions (35-48\%) such as solitary intraductal papilloma and papillomatosis, this discharge can rarely be a sign of malignancy. For this reason, surgeons should carefully evaluate the patient's complaints and symptoms.

Although the definition of PND is clear, there is no consensus on who will undergo microductectomy. Within the scope of this study, the rate of intraductal lesion detection by microductectomy was $63.6 \%$ (35/55: 21 SP, 7 MP, 5 DCIS, 2 intraductal papillary carcinomas) in the whole patient group. It is seen that this rate is higher when compared with the other in the literature. The reason for this is that patients who meet all PND criteria are given priority in order to avoid unnecessary surgery when making a surgical decision, since there is no possibility to perform ductoscopy. The primary criterion for the surgical decision was the color of the discharge. Also, the discharge of all patients in the study was a single duct.

In the literature, when the color of the discharge is not taken into account, the rates of PNML in patients who are decided to be operated according to the results of ductoscopy are between $7 \%$ and $13 \%$ [14-16]. If the color of the discharge is bloody, this rate increases up to $31 \%[17,18]$. This rate has been reported as $10 \%$ in patients who underwent ductus excision, considering classical imaging methods, cytology and pathological discharge criteria without ductoscopy $[19,20]$. In this study, the PNML rate was $18.1 \%(10 / 55)$ in the whole patient group. The PNML rate was $19.5 \%$ (8/41) in patients with PND $3+$ and $14.2 \%(2 / 14)$ in patients with PND 2+. Considering these results, the reason why PNML rates were higher than the examples in the literature was that 2 patients with intraductal papilloma with atypia and 1 patient with intraductal papillomatosis with atypia were included in the PNML group. In addition, if ductoscopy was performed in 1 patient with intraductal papilloma + DCIS, DCIS could be skipped by performing ductoscopic papillectomy. If these 4 patients are excluded from the PNML group, the new rate changes to $10.9 \%(6 / 55)$ and it can be seen that this rate is compatible with the literature. While these results show that ductoscopy is useful in removing single papilloma in an office environment without the need for surgery, it is insufficient to detect PNMLs and the patient may skip it. Nevertheless, when looking at the series in the literature to reach such an opinion, it is seen that the patient group in the study is insufficient. Cytological examination of nipple discharge may be helpful in diagnosis, but alone cannot distinguish $\mathrm{ADH}$, intraductal papilloma and DCIS. In a retrospective study by Kalu et al. [21], The sensitivity of cytology was $74.5 \%$ and the specificity was $30 \%$. Ohlinger et al. [22], İn their retrospective study, found the sensitivity of cytology as $57.8 \%$ and the specificity as $85.2 \%$. In this study, the sensitivity of cytology in detecting intraductal lesions was $74 \%$ and its specificity was $75 \%$.

In the literature, the sensitivity of ultrasonography in detecting the intraductal lesion varies between $56 \%$ and $83 \%$, and the specificity varies between $18 \%$ and $75 \%[22,24,25]$. In this study, the sensitivity of ultrasonography was $45.2 \%$ and the specificity was $75 \%$. The reason for the difference of the sensitivity percentage from the literature is that USG is thought to be a subjective imaging method based on the experience of the person performing it. The specificity of the study was found to be consistent with the literature. The sensitivity of mammography in detecting intraductal lesions in nipple discharge varies between $15 \%$ and $60 \%$ in various studies, and its specificity varies between $65 \%$ and $98 \%$ [23, 24]. Mammography was used in this study to rule out malignancy. The use of MRI is more common in evolving nipple discharge. When looking at the literature, it can be seen that the sensitivity of MRI in various studies varies between $65 \%$ and $100 \%$, and the specificity varies between $12 \%$ and $68 \%[22,24,25]$. In the study conducted, the sensitivity of MRI was found to be $72.2 \%$ and its specificity as $51.4 \%$, and these rates were found to be compatible with the literature.

\section{CONCLUSION}

The findings of this study show that microductectomy performed with the correct indication enables the completion of appropriate treatment by detecting precancerous breast lesions that can be easily missed with 
classical diagnostic methods. At the same time, it provides symptomatic treatment of patients in lesions without malignancy risk. It is thought that it is not a wrong view to consider microductectomy as a priority in women who meet the 2 criteria of nipple discharge. In cases where direct intraductal imaging methods cannot be applied in patients admitted to the polyclinic with pathological nipple discharge, microductectomy emerges as an effective diagnosis and treatment method that can be applied with low morbidity.

\section{Authors' Contribution}

Study Conception: AEK, MMA, FM; Study Design:AEK, MMA, FM; Supervision: AEK, MMA, FM; Funding:AEK, MMA, FM; Materials: AEK, MMA, FM; Data Collection and/or Processing: AEK, MMA, FM; Statistical Analysis and/or Data Interpretation: AEK, MMA, FM; Literature Review: AEK, MMA, FM; Manuscript PreparationAEK, MMA, FM and Critical Review: AEK, MMA, FM.

\section{Conflict of interest}

The authors disclosed no conflict of interest during the preparation or publication of this manuscript.

\section{Financing}

The authors disclosed that they did not receive any grant during conduction or writing of this study.

\section{REFERENCES}

1. Florio MG, Manganero T, Pollicino A, Scarfo P, Micali B. Surgical approach to nipple discharge: a ten year experience. J Surg Oncol 1999;71:235-8.

2. Doğan BE, Tükel S. Meme akıntısına radyolojik yaklaşım. Türk Tanısal ve Girişimsel Radyoloji Dergisi 2002;8:364-71.

3. Klimberg VS. Nipple discharge: more than pathologic. Ann Surg Oncol 2003;10:98-9.

4. Ballesio L, Maggi C, Savelli S, Angeletti M, De Felice C, Meggiorini $\mathrm{ML}$, et al. Role of breast magnetic resonance imaging (MRI) in patients with unilateral nipple discharge: preliminary study. Radiol Med 2008;113:249-64.

5. Orel SG, Dougherty CS, Reynolds C, Czerniecki BJ, Siegelman ES, Schnall MD. MR imaging in patients with nipple discharge: initial experience. Radiology 2000;216:248-54.

6. Carty NJ, Mudan SS, Ravichhandran D, Royle GT, Taylor I. Prospective study of outcome in women presenting nipple discharge. Ann R Coll Surg Engl 1994;76:387-9.

7. Matsunaga T, Misaka T, Hosokawa K, Taira S, Kim K, Serizawa $\mathrm{H}$, et al. Intraductal approach to the detection of intraductal lesions of the breast. Breast Cancer Res Treat 2009;118:9-13 8. Morrogh M, Morris EA, Liberman L, Borgen PI, King TA. The predictive value of ductography and magnetic resonance imaging in the management of nipple discharge. Ann Surg Oncol 2007; 14:3369-77.

9. Kapenhas-Valdes E, Feldman SM, Cohen JM, Boolbol SK. Mammary ductoscopy for evaluation of nipple discharge. Ann Surg Oncol 2008;15:2720-7.

10. Dawes LG, Bowen C, Venta LA, Morrow W. Ductography for nipple discharge: no replacement for ductal excision. Surgery 1998;124:685-91.

11. Simmons R, Adamovich T, Brennan M, Christos P, Schultz $\mathrm{M}$, Eisen $\mathrm{C}$, et al. Nonsurgical evaluation of pathologic nipple discharge. Ann Surg Oncol 2003;10:113-6.

12. Dietz JR, Crowe JP, Grundfest S, Arrigain S, Kim JA. Directed duct excision by using mammary ductoscopy in patients with pathologic nipple discharge. Surgery 2002;132:582-7.

13. Sharma R, Dietz J, Wright H, Crowe J, DiNunzio A, Woletz $\mathrm{J}$, et al. Comparative analysis of minimally invasive microductectomy versus major duct excision in patients with pathologic nipple discharge. Surgery 2005;138:591-6.

14. Fisher CS,Margenthaler JA. A look into the ductoscope: its role in pathologic nipple discharge. Ann Surg Oncol 2011;18:3187-91.

15. Yang X, Li H, Gou J, Tan Q, Wang L, Lin X, et al. The role of breast ductoscopy in evaluation of nipple discharge: a chinese experience of 419 patients. Breast J 2014;20:388-93.

16. Kamali S, Harman Kamali G, Alkan A, Simşek S, Bender O. Use of ductoscopy as an additional diagnostic method and its applications in nipple discharge.Minerva Chir2014;69:65-73.

17. Fajdic J, Gotovac N, Glavic Z, Hrgovic Z, Jonat W, Schem C. Microduchectomy in the management of pathologic nipple discharge. Arch Gynecol Obstet 2011;283:851-4.

18. Matsunaga T, Ohta D, Misaka T, Hosokawa K, Fujii M, Kaise $\mathrm{H}$, et al. Mammary ductoscopy for diagnosis and treatment of intraductal lesions of the breast. Breast Cancer 2001;8:213-21.

19. Tang SSK, Twelves DJ, Isacke CM, Gui GPH. Mammary ductoscopy in the current management of breast disease. Surg Endosc 2011:25:1712-22.

20. Sabel MS,Helvie MA,Breslin T, Curry A, Diehl KM, Cimmino VM, et al. Is duct exicision stil necessary for all cases of suspicious nipple discharge? Breast J 2012;18:157-62.

21. Kalu ON,Chow C,Wheeler A, Kong C, Wapnir I. The diagnostic value of nipple discharge cytology: breast imaging complements predictive value of nipple discharge cytology. J Surg Oncol 2012;106:381-5.

22. Ohlinger R,Stomps A, Paepke S, Blohmer JU, Grunward S, Hahndorf W, et al. Ductoscopic detection of intraductal lesions in cases of pathologic nipple discharge in comparison with standard diagnostics:the German multicenter study.Oncol Res Treat 2014;37:682-32.

23. Bahl M,Baker JA, Greenup RA, Ghate SV. Diagnostic value of ultrasound in female patients with nipple discharge. AJR Am J Roentgenol 2015;205:203-8.

24. Grunwald S, Heyer H, Paepke S, Schwesinger G, Schimming A, Hahn M, et al. Diagnostic value of ductoscopy in the diagnosis of nipple discharge and intraductal proliferations in comparison 
to standard methods. Oncologie 2007;30:243-8.

pathologic nipple discharge: what is the added diagnostic value 25. Bahl M,Baker JA, Greenup RA, Ghate SV. Evaluation of 